12 years. There is clearly a need for a new and more emphatic approach to this health hazard.

In general, the picture portrayed by the 1970 British Births Survey is one of continuing, steady progress with lowering mortality rates, but there is no doubt that much can still and must be done to improve the care of pregnant women in Britain. We must strive to identify more precisely those pregnancies where there is an increased risk and ensure that special attention and skills are given to these mothers. Equally important is the need to explore every means of educating the mothers themselves so that every advantage is taken of facilities at present available.

${ }^{1}$ Reports on Confidential Enquiries into Maternal Deaths in England and Wales 1952-1972. London, HMSO, 1957-1975.

${ }^{2}$ Maternity in Great Britain: Report of the 1946 Survey. London, Oxford University Press, 1948.

${ }^{3}$ Butler, N R, and Bonham, D G, Perinatal Mortality. Edinburgh, E and S Livingstone, 1963.

${ }^{4}$ Butler, N R, and Alberman, E D, Perinatal Problems. Edinburgh, E and S Livingstone, 1969.

${ }^{5}$ British Births 1970, The First Week of Life. London, Heinemann, 1975.

${ }^{6}$ Illsley, R, British Medical fournal, 1955, 2, 1520.

\section{Whose responsibility?}

The important lesson of the inquiry into St Augustine's Hospital, Chartham, Canterbury, ${ }^{1}$ is that no one took overall responsibility for the care of the patients with chronic mental disorders. The rest of the staff saw the consultant psychiatrists as leaders; and, says the report, they were content to be so cast, but they did nothing to lead the long-stay wards away from custodial care. In consequence the nurses-struggling to cope in overcrowded, disturbed wards with less than adequate staff-set themselves the objective of keeping their patients quiet and out of trouble and nothing more. No one need be surprised that in such a depressing environment there were examples of ill treatment and neglect.

Unlike its predecessors, however, this inquiry has made positive suggestions for reform that could lead to a fundamental change in attitudes. It argues a convincing case for multidisciplinary teams at three levels-hospital, clinical area, and ward-which would agree on treatment policies and on the way they should be put into practice. These teams would include doctors, nurses, administrators, psychologists, social workers, occupational therapists, and representatives from the patients, and would be responsible for setting standards and ensuring that they were met.

Over-stretched as the psychiatric services are, at present the chronic patients in many long-stay wards get little attention from medical staff dealing most of the time with the overwhelming load of acute mental illness. The multidisciplinary approach would give the nurses and therapists who spend their working days with chronic patients a chance to initiate variations in treatment and help formulate policies on the management of violence and the handling of complaints and would encourage activities such as outings for patients. This team concept would introduce no conflict with clinical responsibility, for, while a diagnosis or the prescription of a drug by a doctor may be influenced by information provided by a psychologist or a nurse, the final responsibility is, and must remain, his.

The second initiative in the St Augustine's report is its emphasis on the need for effective surveillance of standards of care. "Far too much monitoring consists of waiting to be told and then taking no effective action when information does come," says the report, and it is only too clear that a monitoring system may degenerate into a complaints procedure. What is needed-not only in mental hospitals but elsewhere in the NHS -is a more positive approach to medical audit, for constructive criticism has an important role in improving clinical standards.

Too much optimism would, unfortunately, be unrealistic; for there is one major obstacle to these proposals. Almost any mental hospital could embark on a programme of revitalisation of therapeutic effort in its long-stay wards, carrying along medical and nursing staff in a wave of enthusiasm, and some have already done so. But, as we have emphasised so often before, ${ }^{2-4}$ such treatment programmes must have discharge from hospital as their long-term objective; and most of the communities into which the patients would be discharged have done little to provide accommodation or other facilities for them. There can be no coherent policy for the treatment of mental illness so long as the community services remain so grossly inadequate.

\footnotetext{
${ }^{1}$ Report of committee of inquiry at St Augustine's Hospital, Chartham. South-east Thames Regional Health Authority, 1976.

2 British Medical fournal, 1966, 2, 655.

${ }^{3}$ British Medical fournal, 1973, 3, 1.

${ }^{4}$ British Medical fournal, 1976, 1, 111.
}

\section{Food choking and the "Heimlich maneuver"'}

"Each year, 3900 healthy individuals in the United States
strangle because of food stuck in their throats. The actual
incidence is probably much higher, as indicated by a report of
unsuspected food choking found at postmortem examinations
of three patients thought to have died from myocardial
infarctions in one nursing home last year." So opened a
dramatic article in $7 A M A^{1}$ by Dr Henry J Heimlich, who went
on to describe the "Heimlich maneuver," a procedure designed
to disimpact a food bolus lodged at the laryngeal orifice. This
depends on a quick upward thrust on the diaphragm by
pressure on the epigastrium in an inward and upward direction.
The idea is to produce a sudden sharp rise of intrathoracic
pressure which will eject the bolus like a cork out of a bottle.
The procedure can be performed with the casualty standing
or lying. The article also describes a standard signal for "I am
choking on food," in which the victim graspshis neck between
the index finger and thumb: the idea is that bystanders will
then be alerted to act swiftly and effectively.
The incidence of these so-called café coronaries appears to
be higher in the United States than in Britain. Category E911
in the International Classification of Diseases includes
"inhalation and ingestion of food causing obstruction or
suffocation." There were 176 deaths in Britain from this cause
in 1972 among men and women aged 3-59 years and a further
121 among those aged 60 or more.
deaths in babies, but some at least of these must have been
examples of the sudden infant death syndrome diagnosed in
old-fashioned terms. Further examination of these deaths show
that most occur in old people in institutions and a few in young adults who vomit after drinking alcohol.

In Britain, then, the problem does not seem large-possibly because the potentially lethal practice of drinking whisky with 